\title{
APPLICATION OF THE PERFORMANCE SELECTION INDEX METHOD FOR SOLVING MACHINING MCDM PROBLEMS
}

\author{
UDC 519.8:621.9
}

\author{
Dušan Petković ${ }^{1}$, Miloš Madić ${ }^{1}$, Miroslav Radovanović ${ }^{1}$, \\ Valentina Gečevska \\ ${ }^{1}$ Faculty of Mechanical Engineering, University of Niš, Serbia \\ ${ }^{2}$ Faculty of Mechanical Engineering, University in Skopje, Macedonia
}

\begin{abstract}
Complex nature of machining processes requires the use of different methods and techniques for process optimization. Over the past few years a number of different optimization methods have been proposed for solving continuous machining optimization problems. In manufacturing environment, engineers are also facing a number of discrete machining optimization problems. In order to help decision makers in solving this type of optimization problems a number of multi criteria decision making (MCDM) methods have been proposed. This paper introduces the use of an almost unexplored MCDM method, i.e. performance selection index (PSI) method for solving machining MCDM problems. The main motivation for using the PSI method is that it is not necessary to determine criteria weights as in other MCDM methods. Applicability and effectiveness of the PSI method have been demonstrated while solving two case studies dealing with machinability of materials and selection of the most suitable cutting fluid for the given machining application. The obtained rankings have good correlation with those derived by the past researchers using other MCDM methods which validate the usefulness of this method for solving machining MCDM problems.
\end{abstract}

Key Words: Multi Criteria Decision Making, Performance Selection Index, Machining, Optimization, Machinability, Cutting Fluid

\section{INTRODUCTION}

Machining is one of the most important and widely used manufacturing processes. It is a process of material removal using cutting tools and machine tools to accurately obtain the required product dimensions with good surface finish [1]. There are many different machining processes while each of them represents a very complex and highly

Received November 20, 2015 / Accepted May 20, 2016

Corresponding author: Dušan Petković

University of Niš, Faculty of Mechanical Engineering, A. Medvedeva 14, Niš, Serbia

E-mail: dusan.petkovic@masfak.ni.ac.rs 
nonlinear multi-input multi-output process. The machining process is performed in the specific tribo-mechanical system consisting of five basic groups of input parameters such as workpiece, machine tool, cutting tool, interface and cutting conditions. In machining processes practically any parameter within these groups can be varied in a wide range. This results in the change of machining performances including cutting forces, surface roughness, temperature in the cutting zone, chip formation, noise, tool wear, etc [2]. Appropriate selection of workpiece and tool materials, machine tools, cutting fluids, cutting conditions and sequences is a key factor in achieving minimum cost of production or a maximum production rate, or an optimum combination of both, along with better product quality in machining [1].

Numerous manufacturing firms typically select machining parameters i.e. machining conditions based on the machinist's experience, handbook recommendations or the use of time consuming trial and error approach. However, this type of selection does not guarantee achieving optimum machining performances. The more advanced approach is based on the integration of empirical models based on the regression analysis or artificial neural networks with an optimization method. Typical application examples include the application of classical optimization methods and modern meta-heuristic algorithms (such as genetic algorithms, simulated annealing, harmony search, etc.) for determining optimal machining conditions with the ultimate aim to improve surface finish, minimize tool wear, maximize productivity, minimize cost or achieve some combinations of these goals. The application of the Taguchi method is also an attractive alternative, particularly in the case of multi-objective optimization problems; however, in this case one needs to integrate it with grey relational analysis, principal component analysis or utility approach. In essence, the application of the Taguchi method is particularly popular since it determines robust machining conditions, i.e. machining conditions which are insensitive with respect to all causes of variation (noise factors). Noise factors (external conditions, manufacturing imperfections, etc.) are unwanted sources of variation and can be uncontrollable or too expensive to control. The Taguchi method application has become very popular because it represents a model-free optimization method that can be readily applied avoiding, in some cases, time consuming empirical model development.

Integration of empirical models and optimization methods allows for continuous single and multi-criteria optimization of machining processes. In this case, values of independent variables (machining parameters) are defined in continual or integer domain and the goal is to determine the best solution which satisfies all previously set constraints and ranges of independent variables. On the other hand, there are single and multi-criteria optimization problems where there exist a finite number of pre-known solutions (alternatives). For solving these types of optimization problems, a number of methods have been developed and these are in literature known as multi criteria decision making (MCDM) methods. In open literature, solving machining MCDM problems using MCDM methods is mainly related to machinability of materials and selection of cutting fluids [1, 3-7]. Past research investigated the applicability of a number of MCDM methods including graph theory and matrix approach (GTMA), technique for order preference by similarity to ideal solution (TOPSIS), weighted aggregated sum product assessment (WASPAS), and preference ranking organization method for enrichment evaluation (PROMETHEE).

While solving different MCDM problems there is a continuous need for a systematic and simple mathematical method for efficient and effective evaluation of solutions, i.e. alternatives. This paper is focused on the investigation of applicability and suitability of 
the performance selection index (PSI) method for solving machining MCDM problems. To the authors' best knowledge, the PSI method has not been previously applied to solving machining MCDM problems. The unique characteristic of this method lies in a fact that is not necessary to determine criteria weights as in other MCDM methods; this was the main motivation to use this MCDM method. Two real time case studies were solved using this method and the obtained complete rankings were compared with the previously obtained ones by other MCDM methods.

\section{PREFERENCE SELECTION INDEX (PSI) METHOD}

The PSI method was proposed by Maniya and Bhatt [8] in 2010 for solving material selection MCDM problems. Unlike the most MCDM methods, the PSI method does not require determination of the relative importance of the criteria, and, therefore, it is not necessary to determine criteria weights. Thus, the method is particularly useful in the cases where a conflict in deciding the relative importance among criteria appears [9]. Actually, the PSI method determines criteria weights only by using information provided in the decision matrix, i.e. it uses an objective approach to determine criteria weights like standard deviation or entropy method. The main application procedure of the PSI method for solving MCDM problems includes several steps [8-11]:

Step 1: Determine the objective and identify the relevant criteria for evaluation of the alternatives.

Step 2: Set the initial decision matrix, $\mathrm{X}$ :

$$
X=\left[x_{i j}\right]_{m \times n}=\left[\begin{array}{cccc}
x_{11} & x_{12} & \ldots & x_{1 n} \\
x_{21} & x_{22} & \ldots & x_{2 n} \\
\ldots & \ldots & \ldots & \ldots \\
x_{m 1} & x_{m 2} & \ldots & x_{m n}
\end{array}\right]
$$

where $x_{i j}$ is the assessment value of $\mathrm{i}$-th alternative in respect to $\mathrm{j}$-th criterion, $m$ is the number of alternatives and $n$ is the number of criteria.

Step 3: Determine the normalized decision matrix in which the elements of the matrix are calculated using the following equations:

- for maximization (beneficial) criteria:

$$
\bar{x}_{i j}=\frac{x_{i j}}{x_{i j}^{\max }}, i=1, \ldots, m
$$

- for minimization (non-beneficial) criteria:

$$
\bar{x}_{i j}=\frac{x_{i j}^{\min }}{x_{i j}}, i=1, \ldots, m
$$

Step 4: Determine the mean values of normalized performances in relation to each criterion using the following equation:

$$
N=\frac{1}{n} \sum_{i=1}^{m} \bar{x}_{i j}
$$


Step 5: Determine the values of the variation of preferences in relation to each criterion using the following equation:

$$
\phi_{j}=\sum_{i=1}^{m}\left(\bar{x}_{i j}-N\right)^{2}
$$

Step 6: Determine the deviations of the value of the preference in relation to each criterion using the following equation:

$$
\Omega_{j}=1-\phi_{j}
$$

Step 7: Determine the criteria weights using the following equation:

$$
w_{j}=\frac{\Omega_{j}}{\sum_{j=1}^{n} \Omega_{j}}
$$

Step 8: Determine the preference selection index of alternatives using the following equation:

$$
\theta_{i}=\sum_{j=1}^{n} \bar{x}_{i j} w_{j}
$$

Step 9: Based on the preference selection index values of the alternatives, determine the complete ranking of alternatives. The alternative which has the largest preference selection index represents the best ranked alternative.

\section{CASE STUDIES}

In this paper, an attempt is made to prove and validate the applicability of the PSI method by taking into consideration two real time machining MCDM problems, i.e. analysis of materials machinability and selection of cutting fluids for a given machining application. The main objective is to compare the performance of the PSI method with the other known MCDM methods for solving machining MCDM problems.

\subsection{Machinability of materials - Case study 1}

The machinability of a material represents complex technical characteristic, expressed by the measure in which the material can be satisfactorily machined [7]. The machinability aspect is of considerable importance since it is necessary for production engineers to know in advance the machinability of work materials so that machining can be planned in an efficient manner. The study can also be a basis for cutting tool and cutting fluid performance evaluation and machining parameter optimization [1].

Enache et al. [7] proposed a new mathematical model for the establishment of the partial and global machinability of materials. The mathematical model is verified experimentally in the case of turning of titanium alloys using different cutting tools of different geometries. Turning experiments have been performed without the use of cutting fluid, using cutting speed of $150 \mathrm{~m} / \mathrm{min}$, feed rate of $0.15 \mathrm{~mm} / \mathrm{rev}$ and depth of cut of $0.5 \mathrm{~mm}$. Six workpiece-tool material combinations (TiAl6V4-P20, TiMo32-P20, 
TiAl5Fe2.5-P20, TiAl6V4-P20 (TiN), TiAl6V4-K20 and TiAl6V4-K20*) and three evaluation criteria such as tool wear rate (TWR), specific energy consumed (SEC) and surface roughness (SR) are considered. Experimental results are given in Table 1.

Table 1 Decision matrix for case study 1 [7]

\begin{tabular}{lccc}
\hline Work-tool combination & $\begin{array}{c}\text { TWR } \\
(\mathrm{m} / \mathrm{min})\end{array}$ & $\begin{array}{c}\text { SEC } \\
(\mathrm{J})\end{array}$ & $\begin{array}{c}\text { SR } \\
(\mu \mathrm{m})\end{array}$ \\
\hline (1) TiAl6V4-P20 & 0.061 & 219.74 & 5.8 \\
(2) TiMo32-P20 & 0.093 & 3523.72 & 6.3 \\
(3) TiAl5Fe2.5-P20 & 0.064 & 2693.21 & 6.8 \\
(4) TiAl6V4-P20 (TiN) & 0.028 & 761.46 & 5.8 \\
(5) TiAl6V4-K20 & 0.034 & 1593.48 & 5.8 \\
(6) TiAl6V4-K20* & 0.013 & 2849.15 & 6.2 \\
\hline
\end{tabular}

In this study all three criteria are minimization criteria i.e. lower attribute values of alternatives are preferred. In other words, the materials machinability is better if during machining low values of TWR. SEC and SR occur. Enache et al. [7] determined criteria weights as $\mathrm{w}_{\mathrm{TWR}}=0.688, \mathrm{w}_{\mathrm{SEC}}=0.231$ and $\mathrm{w}_{\mathrm{SR}}=0.081$ and the same were used by Rao and Gandhi [12], Rao [3] and Chakraborty and Zavadskas [4] while applying graph theory and matrix approach (GTMA), TOPSIS and WASPAS methods, respectively.

\subsection{Selection of cutting fluids - Case study 2}

During machining lubricants/cutting fluids have different effects including cooling, lubricating, mechanics, diffusing and washing. Since cutting fluids serve many useful functions during machining, and, on the other hand, incur one portion of the total manufacturing cost, the appropriate selection of cutting fluids is very important.

Rao and Patel [6] applied PROMETHEE method for solving cutting fluid selection problem for a cylindrical grinding operation. Four cutting fluids, i.e. alternatives, were evaluated based on eight criteria such as wheel wear (WW), tangential force (TF), grinding temperature (GT), surface roughness (SR), recyclability $(\mathrm{R})$, toxic harm rate $(\mathrm{TH})$, environment pollution tendency (EP) and stability (S). Alternative attributes with respect to $\mathrm{R}, \mathrm{TH}, \mathrm{EP}$ and $\mathrm{S}$ were expressed linguistically and subsequently were transformed into real crisp values using fuzzy scales [1]. Decision matrix for this case study is given in Table 2.

Among the eight criteria, only $\mathrm{R}$ and $\mathrm{S}$ are the maximization criteria where higher attribute values of alternatives are preferred. By using the AHP method, Rao and Patel [6] determined criteria weights as: $\mathrm{w}_{\mathrm{ww}}=0.3306, \mathrm{w}_{\mathrm{TF}}=0.0718, \mathrm{w}_{\mathrm{GT}}=0.1808, \mathrm{w}_{\mathrm{SR}}=0.0718$, $\mathrm{w}_{\mathrm{R}}=0.0459, \mathrm{w}_{\mathrm{TH}}=0.126, \mathrm{w}_{\mathrm{EP}}=0.126$ and $\mathrm{w}_{\mathrm{S}}=0.0472$. This set of criteria weights was also used by Chakraborty and Zavadskas [4] whereas the WASPAS method was applied.

Table 2 Decision matrix for case study 2 [6]

\begin{tabular}{ccccccccc}
\hline $\begin{array}{c}\text { Cutting } \\
\text { fluid }\end{array}$ & $\begin{array}{c}\text { WW } \\
(\mathrm{mm})\end{array}$ & $\begin{array}{c}\text { TF } \\
(\mathrm{N})\end{array}$ & $\begin{array}{c}\text { GT } \\
\left({ }^{\circ} \mathrm{C}\right)\end{array}$ & $\begin{array}{c}\text { SR } \\
(\mu \mathrm{m})\end{array}$ & $\mathrm{R}$ & $\mathrm{TH}$ & $\mathrm{EP}$ & $\mathrm{S}$ \\
\hline 1 & 0.035 & 34.5 & 847 & 1.76 & $\mathrm{~L}(0.335)$ & $\mathrm{A}(0.5)$ & $\mathrm{AA}(0.59)$ & $\mathrm{AA}(0.59)$ \\
2 & 0.027 & 36.8 & 834 & 1.68 & $\mathrm{~L}(0.335)$ & $\mathrm{H}(0.665)$ & $\mathrm{H}(0.665)$ & $\mathrm{H}(0.665)$ \\
3 & 0.037 & 38.6 & 808 & 2.4 & $\mathrm{AA}(0.59)$ & $\mathrm{AA}(0.59)$ & $\mathrm{BA}(0.41)$ & $\mathrm{A}(0.5)$ \\
4 & 0.028 & 32.6 & 821 & 1.59 & A $(0.5)$ & AA $(0.59)$ & AA $(0.59)$ & BA $(0.41)$ \\
\hline
\end{tabular}

$\mathrm{L}$ - low; BA - below average; A - average; AA: above average; $\mathrm{H}$ - high 


\section{RESULTS AND DISCUSSION}

\subsection{Application of the PSI method}

The detailed computational procedure of the PSI method for solving the afore-stated machining MCDM problems is as follows. Since decision matrices for both case studies are already given, the application of the PSI method starts with step 3. By using Eq. 2 the normalized decision matrix for case study 1 is obtained as shown in Table 3 . The purpose of normalization is to obtain dimensionless values of alternative attribute values so that all these alternatives can be easily evaluated.

Table 3 Normalized decision matrix for case study 1

\begin{tabular}{lll}
\hline 0.2131 & 1.0000 & 1.0000 \\
0.1398 & 0.0624 & 0.9206 \\
0.2031 & 0.0816 & 0.8529 \\
0.4643 & 0.2886 & 1.0000 \\
0.3824 & 0.1379 & 1.0000 \\
1.0000 & 0.0771 & 0.9355 \\
\hline
\end{tabular}

Using the data from Table 3, and by applying Eq. 3, mean values of normalized performances in relation to each criterion are obtained as $\mathrm{N}=[0.4004,0.2746,0.9515]$. Subsequently by applying Eq. 4 values of the variation of preferences in relation to each criterion are calculated (Table 4).

By using Eq. 5 deviations of the value of the preference in relation to each criterion is obtained as $\Omega_{j}=[0.4942,0.3336,0.982]$. Subsequently, by using Eq. 6 criteria weights are determined as $\mathrm{w}=[0.273,0.1843,0.5426]$. Finally, by using Eq. 7 preference selection indexes of alternatives are determined upon which complete ranking of alternatives is obtained (Table 5).

Table 4 Values of the variation of preferences for case study 1

\begin{tabular}{lll}
\hline 0.0351 & 0.5262 & 0.0024 \\
0.0679 & 0.0450 & 0.0010 \\
0.0389 & 0.0372 & 0.0097 \\
0.0041 & 0.0002 & 0.0024 \\
0.0003 & 0.0187 & 0.0024 \\
0.3595 & 0.0390 & 0.0003 \\
\hline
\end{tabular}

Table 5 Performance selection index values of alternatives and complete ranking for case study 1

\begin{tabular}{ccccccc}
\hline Work-tool & TiAl6V4 & TiMo32 & TiAl5Fe2.5 & TiAl6V4 & TiAl6V4 & TiAl6V4 \\
combination & -P20 & -P20 & -P20 & -P20 (TiN) & -K20 & -K20* \\
\hline$\theta_{i}$ & 0.7851 & 0.5492 & 0.5333 & 0.7226 & 0.6724 & 0.7949 \\
Rank & 2 & 5 & 6 & 3 & 4 & 1 \\
\hline
\end{tabular}

From Table 5 it is observed that the ranking of machinability of titanium alloy-based work materials determined by the PSI method is 2-5-6-3-4-1. Thus maximum machinability is obtained with work-tool combination TiAl6V4-K20*. 
Again, the detailed computational procedure of the PSI method for selection of cutting fluids is as follows. By using Eq. 2 the normalized decision matrix is obtained (Table 6).

Table 6 Normalized decision matrix for case study 2

\begin{tabular}{llllllll}
\hline 0.7714 & 0.9449 & 0.9540 & 0.9034 & 0.5678 & 1.0000 & 0.6949 & 0.8872 \\
1.0000 & 0.8859 & 0.9688 & 0.9464 & 0.5678 & 0.7519 & 0.6165 & 1.0000 \\
0.7297 & 0.8446 & 1.0000 & 0.6625 & 1.0000 & 0.8475 & 1.0000 & 0.7519 \\
0.9643 & 1.0000 & 0.9842 & 1.0000 & 0.8475 & 0.8475 & 0.6949 & 0.6165 \\
\hline
\end{tabular}

Using the data from Table 6, and by applying Eq. 3, mean values of normalized performances in relation to each criterion are obtained as $\mathrm{N}=[0.8664,0.9188,0.9767$, $0.8781,0.7458,0.8617,0.7516,0.8139]$. Subsequently by applying Eq. 4 values of the variation of preferences in relation to each criterion are calculated (Table 7).

Table 7 Values of the variation of preferences for case study 2

\begin{tabular}{llllllll}
\hline 0.0090 & 0.0007 & 0.0005 & 0.0006 & 0.0317 & 0.0191 & 0.0032 & 0.0054 \\
0.0179 & 0.0011 & 0.0001 & 0.0047 & 0.0317 & 0.0121 & 0.0182 & 0.0346 \\
0.0187 & 0.0055 & 0.0005 & 0.0465 & 0.0646 & 0.0002 & 0.0617 & 0.0038 \\
0.0096 & 0.0066 & 0.0001 & 0.0149 & 0.0103 & 0.0002 & 0.0032 & 0.0390 \\
\hline
\end{tabular}

By using Eq. 5 deviations of the value of the preference in relation to each criterion are obtained as $\Omega_{j}=[0.9449,0.9861,0.9988,0.9333,0.8617,0.9684,0.9136,0.9172]$. Subsequently, by using Eq. 6 criteria weights are determined as $\mathrm{w}_{\mathrm{j}}=[0.1256,0.1311$, $0.124,0.1145,0.1287,0.1214,0.1219]$. Finally, by using Eq. 7 preference selection indexes of alternatives are determined upon which complete ranking of alternatives is obtained (Table 8).

Table 8 Performance selection index values of alternatives and complete ranking for case study 2

\begin{tabular}{lcccc}
\hline Cutting fluid & 1 & 2 & 3 & 4 \\
\hline$\theta_{i}$ & 0.8457 & 0.8463 & 0.8539 & 0.8725 \\
Rank & 4 & 3 & 2 & 1 \\
\hline
\end{tabular}

As could be seen from Table 8 by applying the PSI method, the ranking of cutting fluids is obtained as 4-3-2-1. In other words, cutting fluid 4 is observed to be the most appropriate for this machining application. Cutting fluid 3 has the second preference and cutting fluid 1 is the least favored.

\subsection{Comparison of complete rankings}

The afore-stated machining MCDM problems were solved by past researchers using different MCDM methods. In this section the comparison of the obtained complete rankings is presented. It has to be noted that the past research while applying different MCDM methods used different set of criteria weights, which significantly affected final rankings. 
Rao and Gandhi [12], Rao [3] and Chakraborty and Zavadskas [4] solved case study 1 applying GTMA, TOPSIS and WASPAS methods, respectively. The comparison of the complete rankings obtained by different MCDM methods and the PSI method is given in Fig. 1.

The results show some difference between the PSI and other MCDM methods. The reason for this is the fact that the other methods performed the analysis using the criteria weights as $\mathrm{w}_{\mathrm{TWR}}=0.688, \mathrm{w}_{\mathrm{TWR}}=0.231$ and $\mathrm{w}_{\mathrm{SR}}=0.081$ while the criteria weights determined by the PSI method were $\mathrm{w}_{\mathrm{TWR}}=0.273, \mathrm{w}_{\mathrm{TWR}}=0.1843$ and $\mathrm{w}_{\mathrm{SR}}=0.5426$. Thus, a drastic change in the priorities among criteria is evident so that one can explain differences in the obtained rankings of alternatives. However, it can be observed that work-tool combination 6 (TiAl6V4-K20*) received the highest ranking by all methods as well as by the PSI; hence, it may be unequivocally regarded as the most appropriate for the given machining application. This MCDM model for the analysis of the machinability of materials shows a high degree of robustness since prioritization of alternatives is not significantly affected by drastic changes in the criteria weights.

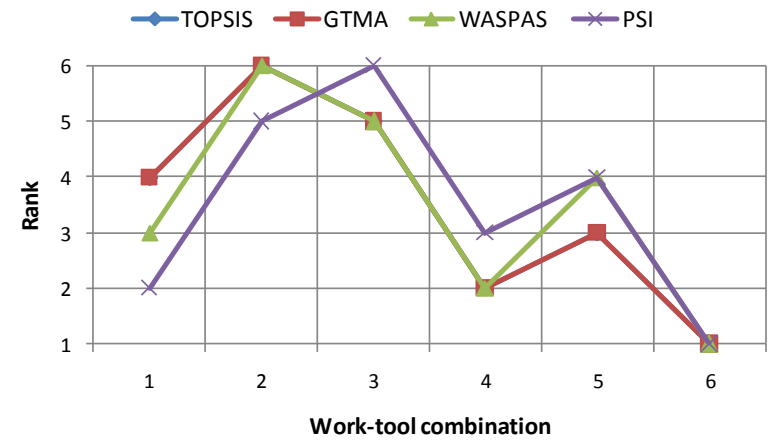

Fig. 1 Comparative rankings of different MCDM methods for case study 1

Rao and Patel [6], Rao [1] and Chakraborty and Zavadskas [4] solved case study 2 while applying PROMETHEE, TOPSIS and WASPAS methods, respectively. The comparison of the complete rankings obtained by different MCDM methods and the PSI method is given in Fig. 2.

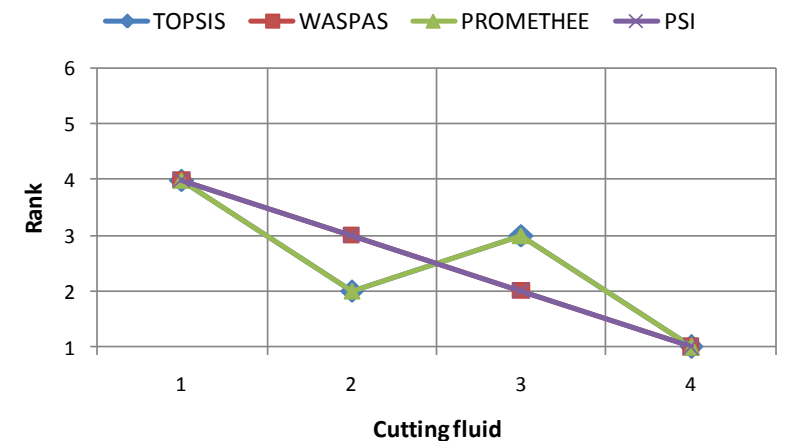

Fig. 2 Comparative rankings of different MCDM methods for case study 2 
From Fig. 2 it can be observed that alternatives rankings obtained by the PSI method perfectly match with those obtained by the WASPAS method. On the other hand, PROMEETHE and TOPSIS method obtained the same rankings of alternatives. However, it is evident that cutting fluid 4 has been identified as the best choice for the given machining application by all MCDM methods. Also, cutting fluid 1 received the worst ranking by all MCDM methods.

\section{CONCLUSION}

In order to improve total machining performances and get the most from machine tool, production engineers formulate different machining optimization problems. This paper presents the application of a new MCDM method i.e. PSI method for solving discrete machining optimization problems. The detail computational procedure of the PSI method is demonstrated while solving two case studies dealing with machinability of materials and selection of the most suitable cutting fluid for the given machining application. The conclusions drawn can be summarized by the following points:

- The obtained rankings have good correlation with those derived by the past researchers using different MCDM methods which validate the usefulness of the PSI method for solving machining MCDM problems. In both case studies, it is observed that the topranked alternatives exactly match with those derived by the past researchers.

- The main advantage and benefit of the PSI method is that it is not necessary to determine criteria weights as in other MCDM methods. Actually, by using only data from decision matrix, the method calculates criteria weights in an objective manner. This unique characteristic has double benefit. First, the cases where there is a conflict in deciding the relative importance among criteria are avoided. Second, the decision making process is accelerated.

- Computational procedure of the PSI method, although performed in nine steeps, is relatively simple and can be easily traced by the decision maker. Solving different MCDM problems by using the PSI method does not requires the use of specialized software packages since the method can be easily implemented in MS Excel.

- By calculating preference selection index values complete ranking of alternatives is enabled.

- Evaluation of alternatives is not affected by the introduction of any additional parameters as it happens in case of other MCDM methods, like $\lambda$ in the WASPAS method.

Finally, it should be noted that further investigation will include possibilities for the PSI method upgrading and comparisons with other MCDM methods for solving different MCDM problems in manufacturing environment.

Acknowledgements: The paper is a part of the research done within the project TR35034 supported by Ministry of Science and Technological Development of the Republic of Serbia. 


\section{REFERENCES}

1. Rao, R. V., 2007, Decision Making in the Manufacturing Environment: using graph theory and fuzzy multiple attribute decision making methods, Springer-Verlag London.

2. Radovanović M., Madić, M., 2010, Methodology of neural network based modeling of machining processes, International Journal of Modern Manufacturing Technologies, 2(2), pp. 77-82.

3. Rao, R.V., 2006, Machinability evaluation of work materials using a combined multiple attribute decision making method, International Journal of Advanced Manufacturing Technology, 28(3-4), pp. 221-227.

4. Chakraborty, S., Zavadskas, E.K., 2014, Applications of WASPAS Method in Manufacturing Decision Making, Informatica, 25(1), pp. 1-20.

5. Petković, D., Madić, M., Radenković, G., 2015, Selection of the Most Suitable Non-Conventional Machining Processes for Ceramics Machining by Using MCDMs, Science of Sintering, 47, pp. 229-235.

6. Rao, R.V., Patel, B.K., 2010, Decision making in the manufacturing environment using an improved PROMETHEE method, International Journal of Production Research, 48(16), pp. 4665-4682.

7. Enache, S., Strajescu, E., Opran, C., Minciu, C., Zamfirache, M., 1995, Mathematical model for the establishment of the materials machinability, CIRP Annals, 44, pp. 79-82.

8. Maniya, K., Bhatt, M.G., 2010, A selection of material using a novel type decision-making method: Preference selection index method, Materials and Design, 31, pp. 1785-1789.

9. Singh T., Patnaik A, Gangil B., Chauhan R., 2015, Optimization of tribo-performance of brake friction materials: effect of nano filler, Wear, 324-325, pp. 10-16.

10. Khorshidi R., Hassani A., 2013, Comparative analysis between TOPSIS and PSI methods of materials selection to achieve a desirable combination of strength and workability in Al/SiC composite, Materials and Design, 52, pp. 999-1010.

11. Vahdani, B., Zandieh, M., Tavakkoli-Moghaddam, R., 2011, Two novel FMCDM methods for alternative-fuel buses selection, Applied Mathematical Modelling, 35, pp. 1396-1412.

12. Rao, R.V., Gandhi, O.P., 2002, Digraph and matrix methods for the machinability evaluation of work materials, International Journal of Machine Tools and Manufacture, 42(3), pp. 320-330. 